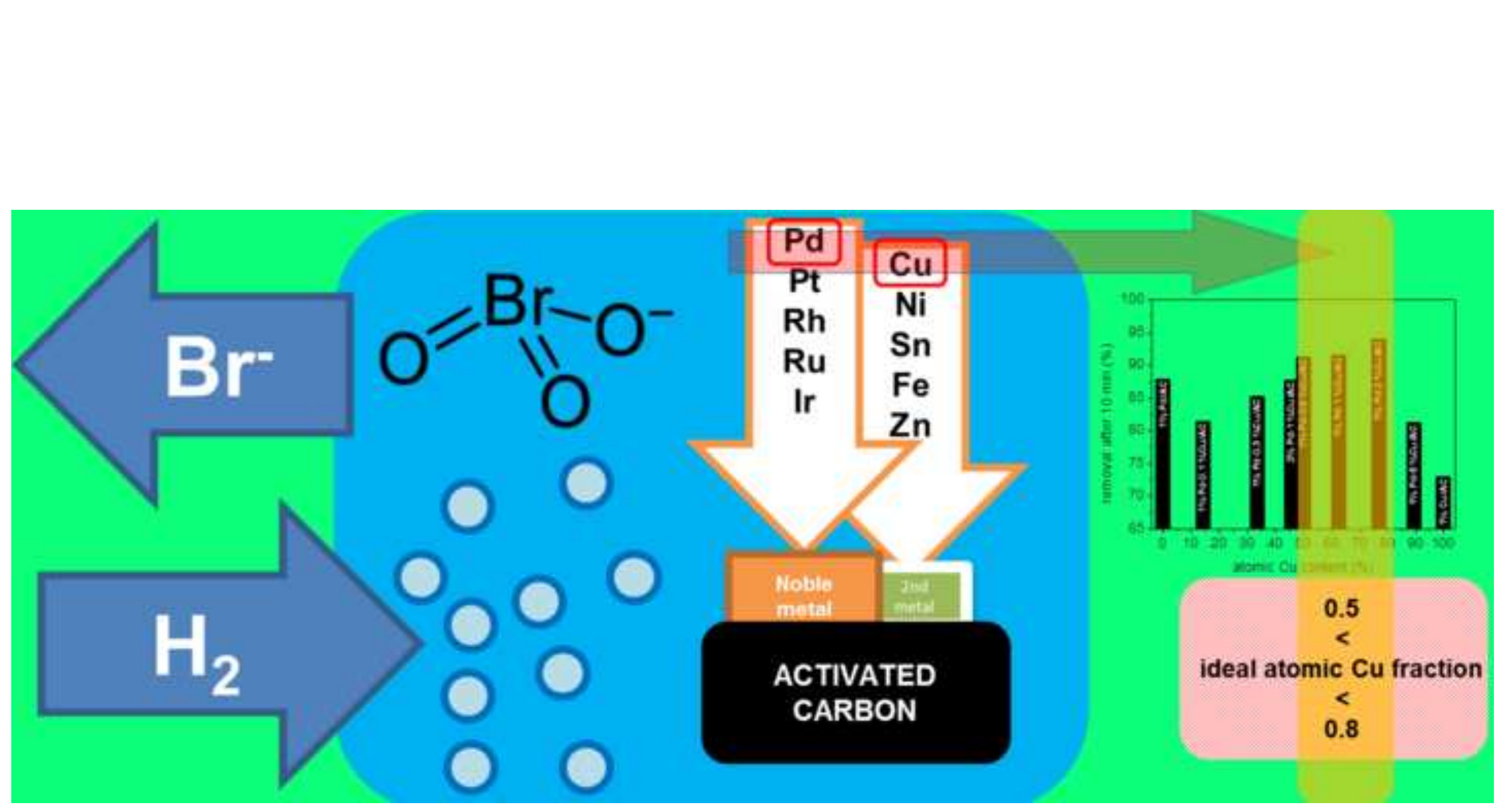




\section{Bimetallic activated carbon supported catalysts for the 2 hydrogen reduction of bromate in water}

3 J. Restivo, O. S. G. P. Soares, J. J. M. Órfão, M. F. R. Pereira*

4 Laboratory of Catalysis and Materials - Associate Laboratory LSRE/LCM, Faculty of

5 Engineering, University of Porto, Rua Dr. Roberto Frias, 4200-465 Porto, Portugal;

$6 \quad *$ Corresponding author: fpereira@fe.up.pt; +351 225081468

7 Abstract

8 The association of bromate in drinking water with several public health risks, namely related to its carcinogenic potential and its toxic nature, has led to an interest in the development of sustainable alternatives for its removal from water. The hydrogen reduction of bromate over supported heterogeneous metallic catalysts has already been shown to be an interesting alternative for the reduction of bromate into less hazardous species, without formation of additional sludges.

In this work, the coupling of a noble metal with a second metal supported on activated carbon has been studied for this reaction. Several metals were used for this goal, resulting in a wide array of combinations of noble and promoter metals. All the combinations showed remarkable activity for the complete conversion of bromate into bromide, without accumulation of by-products.

The role played by the second metal was extensively studied, for which experiments were conducted using physical mixtures of the corresponding monometallic catalysts and also different metal amounts on the supported bimetallic catalysts. In most cases, the presence of a second metal hindered the activity of the noble metal, when compared with the respective monometallic catalyst. In the case of the $\mathrm{Pd}-\mathrm{Cu}$ bimetallic catalyst, it is possible to improve the activity obtained with the Pd catalyst. The activity of the bimetallic catalyst was shown to be dependent on the composition.

Keywords: bromate, hydrogen reduction, bimetallic catalysts, activated carbon 
29

30

Concentrations of bromate in the range 1 to $50 \mu \mathrm{g} / \mathrm{L}$ have been detected in water at full scale water treatment plants [1]. Average concentrations in the United States have been reported to be as high as $100 \mu \mathrm{g} / \mathrm{L}$ [2]. Bromate is mainly derived from the ozonation of bromide containing waters, which reacts with molecular ozone, as well as with the $\mathrm{OH}^{\bullet}$ radicals formed during the process [1-3]. Bromate ion in water may also originate from other sources, such as seawater intrusion, pesticide run-off, industrial wastes and impurities in road de-icing salt [2].

Regarding the dangers associated with the presence of bromate in water, it has been estimated that a concentration of $3.9 \mu \mathrm{g} / \mathrm{L}$ corresponds to a cancer risk of $10^{-5}$ for lifetime exposures [4]. On the other hand, the United States Environmental Protection Agency (USEPA) reports that life-time exposures to 5, 0.5 and $0.05 \mu \mathrm{g} / \mathrm{L}$ lead to cancer risks of $10^{-4}, 10^{-5}$, and $10^{-6}$, respectively [5]. The main risks are associated with the kidneys, both as targets for cancer and for toxic action of bromate. The peritoneum and the thyroid are also considered as cancer targets, and there is also the possibility that exposure to bromate may result in low sperm counts [1]. Both the World Health Organzation (WHO) and USEPA's provisional guidelines limit the concentration of bromate in source water to $0.01 \mathrm{mg} / \mathrm{L}[4,5]$.

The consequent classification of bromate by the International Agency for Research on Cancer in Group 2B (possibly carcinogenic for humans) [6] has led to an interest from the scientific community in the development of technologies for their efficient removal from water.

There are several methods available to remove bromate ion from water, namely adsorption, biological or electrochemical technologies. Nevertheless, the formation of unwanted sludge, and the low efficiency or accumulation in secondary streams leaves space for the development of new technologies [2, 3].

Heterogeneous catalysis has already been demonstrated to be an efficient method for the removal of bromate from water by hydrogen reduction to more desirable species, 
such as bromide $[2,3,7-12]$. Nevertheless, to the best of our knowledge, the potential application of bimetallic catalysts has yet to be tested in this process Such systems have demonstrated potential to enhance the hydrogen reduction of nitrites in water [13-16], which have been reported to have a mechanism similar to that of bromate [7].

The aim of the present work is to determine whether the coupling of a promoter metal and a noble metal supported on activated carbon is advantageous in the catalytic hydrogen reduction of bromate in water, at room temperature and pressure. For that effect, several bimetallic pairs were tested, and some of them were selected to be used in experiments using physical mixtures, which were done to provide information regarding the role of the promoter metal in the reaction. Furthermore, different weight loading ratios were also tried out for a selected bimetallic supported catalyst.

\section{EXPERIMENTAL}

\subsection{Preparation}

A commercial activated carbon (NORIT GAC 1240 PLUS) was used as support. The activated carbon (AC) was ground to a controlled particle diameter between 0.1 and $0.3 \mathrm{~mm}$. The monometallic catalysts were prepared by incipient wetness impregnation and the bimetallic catalysts by incipient wetness co-impregnation, from aqueous solutions of the corresponding metal salts $\left(\mathrm{H}_{2} \mathrm{PtCl}_{6}, \mathrm{PdCl}_{2}, \mathrm{Cu}\left(\mathrm{NO}_{3}\right)_{2}, \mathrm{SnCl}_{2}, \mathrm{RhCl}_{3}, \mathrm{RuCl}_{3}\right.$, $\left.\mathrm{Ni}\left(\mathrm{NO}_{3}\right)_{2},\left(\mathrm{NH}_{4}\right)_{3} \mathrm{IrCl}, \mathrm{Fe}\left(\mathrm{NO}_{3}\right)_{3}, \mathrm{ZnCl} 2\right)$. The contents of both noble and promoter metals were varied between 0.3 and $5 \mathrm{wt} . \%$. After impregnation, the samples were dried at $100 \stackrel{\circ}{\circ}$ for $24 \mathrm{~h}$, calcined under a nitrogen flow at $200{ }^{\circ} \mathrm{C}$ for $1 \mathrm{~h}$, and finally reduced at $200{ }^{\circ} \mathrm{C}$ in hydrogen flow for $3 \mathrm{~h}$. The catalysts prepared are listed in Table 1.

\subsection{Characterization}

Selected catalysts were characterized using different techniques: $\mathrm{H}_{2}$ chemisorption (all bimetallic pairs supported on $A C), \mathrm{N}_{2}$ adsorption at $-196{ }^{\circ} \mathrm{C}(\mathrm{AC}, 2 \% \mathrm{Pd}-1 \% \mathrm{Cu} / \mathrm{AC}$, $1 \% \mathrm{Pt}-1 \% \mathrm{Cu} / \mathrm{AC}$, $1 \% \mathrm{Rh}-1 \% \mathrm{Cu} / \mathrm{AC}$ ), transmission electron microscopy (TEM; 1\%Pd$1 \% \mathrm{Cu}$ ) and scanning electron microscopy coupled with energy-dispersive X-ray 
83

84

85

spectroscopy (SEM-EDS; catalysts characterized after reaction: $1 \% \mathrm{Pd}-1 \% \mathrm{Cu} / \mathrm{AC}$; $1 \% \mathrm{Pd} / \mathrm{AC}+1 \% \mathrm{Cu} / \mathrm{AC})$.

The chemisorption of $\mathrm{H}_{2}$ was carried out at $35 \stackrel{\circ}{\circ} \mathrm{C}$ and atmospheric pressure in an Altamira Instruments AMI-200 apparatus, using the pulse method. The samples were previously calcined and reduced in situ, replicating the treatment conditions used in the preparation of the catalysts described in the previous section. Pulses of $58 \mu \mathrm{L}$ (from a calibrated loop) were successively injected in the carrier gas $\left(25 \mathrm{~cm}^{3} / \mathrm{min}\right.$ of Ar), which passes through a catalyst bed $(150 \mathrm{mg})$, until saturation of the catalyst surface. The non-adsorbed hydrogen is measured with an online thermal conductivity detector.

Textural characterization of the support and of the supported catalysts was based on the analysis of $\mathrm{N}_{2}$ adsorption isotherms, measured at $-196 \stackrel{\circ}{\circ} \mathrm{C}$ with a Nova 4200e (Quantachrome Instruments) equipment.

TEM analyses were obtained using a LEO 906E microscope operating at a $120 \mathrm{kV}$ accelerating voltage.

SEM-EDS analyses were performed using a FEI QUANTA 400 FEG ESEM/EDAX PEGASUS X4M apparatus.

\subsection{EVALUATION OF CATALYSTS}

Bromate reduction was carried out in a semi-batch reactor, equipped with a magnetic stirrer and a thermostatic jacket, at room temperature and atmospheric pressure, and using hydrogen as reducing agent. Initially, $180 \mathrm{~mL}$ of deionised water and $400 \mathrm{mg}$ of catalyst were fed into the reactor, the magnetic stirrer was adjusted to $700 \mathrm{rpm}$ and hydrogen was fed at $100 \mathrm{~cm}^{3} / \mathrm{min}$ during $15 \mathrm{~min}$ to remove oxygen. After that period, $20 \mathrm{~mL}$ of a bromate solution, prepared from $\mathrm{NaBrO}_{3}$, were added to the reactor, in order to obtain an initial $\mathrm{BrO}_{3}$ - concentration equal to $100 \mathrm{mg} / \mathrm{L}$.

Small samples were taken from the reactor for determination of bromate and bromide concentrations after defined periods. Bromate ion concentrations were measured by HPLC using a Hitachi Elite Lachrom apparatus equipped with a diode array detector. 
111 The stationary phase was a Hamilton PRP-X100 column (150 mm x $4.1 \mathrm{~mm}$ ) working at 112 room temperature, under isocratic conditions. The mobile phase was a solution of 0.1 $113 \mathrm{M} \mathrm{NaCl}: \mathrm{CH}_{3} \mathrm{OH}$ (45:55). Bromide ion concentrations were followed using a MetrOHM 114881 Compact Pro ion chromatography apparatus coupled with a 863 Compact 115 Autosampler. An appropriate MetrOHM chromatography column for anions was used 116 with a $3.6 \mathrm{mM} \mathrm{Na}_{2} \mathrm{CO}_{3}$ stationary phase.

\section{RESULTS AND DISCUSSION}

\subsection{ChARACTERIZATION}

119 From $\mathrm{H}_{2}$ chemisorption experiments it was possible to obtain the metal dispersion of the monometallic catalyst [17], but for the bimetallic catalysts no $\mathrm{H}_{2}$ chemisorption was noticed. This may be an indication that some interaction exists between the noble metal (Pd, Pt, Ru, Rh or Ir) and the other metal ( $\mathrm{Cu}, \mathrm{Sn}, \mathrm{Ni}, \mathrm{Zn}$ or $\mathrm{Fe})$, eventually forming an alloy, or the second metal is covering the noble metal, strongly limiting $\mathrm{H}_{2}$ chemisorption.

125 Table 2 shows that the BET surface area of the support is $869 \mathrm{~m}^{2} / \mathrm{g}$. Moreover, it can be observed that the textural parameters of the supported metal catalysts remained practically unchanged compared to the unloaded carbon.

Selected catalysts were analyzed by TEM. In general, the metal is well dispersed on the support, most of the catalysts presenting metal particle diameters between 3 and 7 $\mathrm{nm}$, but in some cases a few larger particles are also observed. Figure 1 shows a representative TEM image of the $1 \% \mathrm{Pd}-1 \% \mathrm{Cu} / \mathrm{AC}$ It was also observed that there are no significant differences in the metal particle size when the amounts of $\mathrm{Pd}$ or $\mathrm{Cu}$ in the Pd-Cu bimetallic catalysts were modified.

\subsection{CATALYTIC EXPERIMENTS}

\subsubsection{BIMETALLIC CATALYSTS}

136 The bromate reduction in the presence of hydrogen was evaluated using several 137 different bimetallic catalysts. To assess this effect, the same activated carbon support 
138 was used for all the metal pairs. The bromine mass balance throughout the 139 experiments presented here showed that the $\mathrm{BrO}_{3}{ }^{-}$was removed from water due to 140 conversion into $\mathrm{Br}^{-}$, with no contribution from adsorption or formation of secondary 141 products.

142 On a first approach, palladium was coupled with different metals. The corresponding 143 bromate removals are shown in Figure 2.

144 The coupling of $\mathrm{Pd}$ with $\mathrm{Cu}$ was shown to be the most efficient combination among 145 those tested, even surpassing the performance of the Pd monometallic catalyst. All the 146 other combinations present similar or lower performances than the Pd monometallic 147 catalyst. A similar trend was observed for the second metal alone, as presented elsewhere: $\mathrm{Cu}>\mathrm{Sn}>\mathrm{Fe}>\mathrm{Zn}$ [17]. Comparison of the performances of the second metals tested alone showed them to be less active than the bimetallic catalysts prepared with Pd.

151 Among the metals tested, the Cu monometallic catalyst shows the best activity both alone [17] and also paired with Pd. Therefore, bimetallic catalysts containing $\mathrm{Cu}$ and different noble metals (Pd, Ir, Pt, Ru) supported on activated carbon were tested in the bromate reduction in the presence of hydrogen, as seen in Figure 3.

155 Once again, the $\mathrm{Pd}-\mathrm{Cu}$ catalyst showed the best performance of those tested, closely 156 followed by the Pt-Cu catalyst. Ir-Cu and Ru-Cu catalysts are outperformed by the $\mathrm{Cu}$ 157 monometallic catalyst in the first 10 and 15 min, respectively, but eventually overpass 158 it, promoting $100 \%$ bromate conversion after 25 and 30 minutes respectively; with the 159 Cu monometallic catalyst total bromate reduction was only achieved after 60 min of 160 reaction. Overall, the performance of every Cu-containing bimetallic catalyst tested 161 here is between that of the Pd-Cu and the Cu monometallic catalyst.

162 To assess the performance of different noble metals in the reduction of bromate using 163 bimetallic catalysts, some noble metals ( $\mathrm{Pd}, \mathrm{Pt}, \mathrm{Ru}$ or $\mathrm{Rh})$ were paired with other 164 metals (Sn or $\mathrm{Ni}$ ) and evaluated in the reaction (Figure 4). 
165 As can be seen in Figure 4, the Pd-Sn catalyst shows the best catalytic activity. Nevertheless, the performance of this catalyst is inferior to that observed with the pair $\mathrm{Pd}-\mathrm{Cu}$ (Figure 3) and also with the Pd monometallic catalyst. In fact, of all the metals that were coupled with the noble metals, copper was the only one that was observed to act as a promoter, while the remaining metals ( $\mathrm{Fe}, \mathrm{Sn}, \mathrm{Zn}, \mathrm{Ni}$ ) used as secondary metals in the bimetallic catalysts were observed to result in worse performances than the corresponding monometallic catalysts. It has been reported that the coupling of Ru and $\mathrm{Ni}$ reduces the total adsorption capacity for $\mathrm{CO}$ in microcalorimetry experiments, approaching that of $\mathrm{Ni}$ alone, probably due to alloy formation [18]. So, the decrease in the bromate reduction performance from the $\mathrm{Ru}$ monometallic catalyst to the $\mathrm{Ru}-\mathrm{Ni}$ bimetallic catalyst must be related to the interaction of the two metals on the surface of the support. In addition, it is known that $\mathrm{H}_{2}$ chemisorption on $\mathrm{Ni}$ is strong [19]. Thus, $\mathrm{Ni}$ might be competing with $\mathrm{Ru}$ for $\mathrm{H}_{2}$ chemisorption. For nitrite reduction, it has been shown that strong absorption of $\mathrm{H}_{2}$ results in lower catalytic activity, with $\mathrm{Ni}$ catalysts supported on activated carbon showing no activity [15]. The Pd, Pt and Rh monometallic catalysts in Figure 4 show better performance than the bimetallic catalysts containing Sn. The coupling of Pt with $\mathrm{Sn}$ in a bimetallic catalyst supported on alumina and prepared at low reduction temperatures has been observed to result in a loss of activity in the hydrogenation of crotonaldehyde, mostly due to the partial blocking of Pt active sites by Sn [20]. The same effect was observed for the conversion of isobutene when the Sn content was higher than 0.5\% [21]. A similar reason can explain why the addition of $\mathrm{Sn}$ reduces the activity of Pd, Pt and Rh in our case.

\subsubsection{PHYSICAL MIXTURES}

Since the monometallic catalysts supported on activated carbon have shown good activities in the hydrogen reduction of bromate in water [17], it is necessary to compare the performance of the monometallic and bimetallic catalysts to understand if there is a synergic effect in the coupling of two different metals, or if the increase in the performance, when observed, is merely due to the higher metal loading available. Therefore, experiments were made using physical mixtures of monometallic catalysts supported on activated carbon. As already mentioned (Figures 2 to 4), the bimetallic catalyst does not always perform better than the monometallic catalyst. When other 
metals were coupled with $\mathrm{Pd}$, only $\mathrm{Cu}$ managed to improve the removal of bromate

197 from water. Thus, the effect of $\mathrm{Cu}$ as a promoter metal was studied when coupled with 198 Pd.

199 The SEM-EDS spectra obtained for the post-reaction recovered catalysts are presented in Figure 5. This analysis was made for recovered catalysts from the experiments using bimetallic catalysts and physical mixtures of monometallic catalysts. The observations shown here were compared with the SEM-EDS spectra obtained with fresh catalysts, as well as those for the corresponding monometallic catalysts [22].

It is observable from the EDS data that, for the bimetallic catalyst, both metals were identified in close contact (Figure 5-a). Similar spectra were obtained for the fresh bimetallic catalysts, as reported elsewhere [22], This suggests that no changes, such as metal leaching or migration, occur during the bromate reduction reactions in the conditions used in the present work, with this catalyst.

For the physical mixture of $1 \% \mathrm{Pd} / \mathrm{AC}$ and $1 \% \mathrm{Cu} / \mathrm{AC}$, both metals were identified in the metal particles where Pd was observed on the surface of the support (Figure 5-d). Only individual $\mathrm{Cu}$ particles were observed (Figure 5-e). This is due to the leaching of $\mathrm{Cu}$, which has also been witnessed when similar experiments were carried out for the hydrogen reduction of nitrates in water [22]. In fact, the leaching of copper in similar supports has been observed by several authors, which leads to the conclusion that in the case of the $\mathrm{Pd} / \mathrm{Cu}$ physical mixture, a bimetallic catalyst, with the metals in close contact, is formed in-situ under the reaction conditions used [22, 23].

217 In Figure 6 the bromate conversions obtained using the $\mathrm{Pd}$ and $\mathrm{Cu}$ system as 218 monometallic catalysts, as a bimetallic catalyst and as a physical mixture of the two monometallic catalysts are compared.

From Figure 6 it is possible to see that the bimetallic catalyst shows better performance than the corresponding monometallic catalysts, as was already stated. Most importantly, the physical mixture of $\mathrm{Pd}$ and $\mathrm{Cu}$ monometallic catalysts presents even higher performance in the bromate reduction than the bimetallic catalyst. This must be related with the disposition of the metals on the support. When a mixture of 
monometallic catalysts is used, all the metal active sites are accessible on the catalyst surface for the bromate reduction, whereas the same may not occur when bimetallic catalysts are used [22], since the most active metal could be covered by the other metal. In fact, during the hydrogen chemisorption analyses no $\mathrm{H}_{2}$ chemisorption was observed on the $\mathrm{Cu}$ and $\mathrm{Pd}-\mathrm{Cu}$ catalysts, as was expected since $\mathrm{Cu}$ does not chemisorb $\mathrm{H}_{2}$ [24]. This may indicate that some interaction between the noble metal and $\mathrm{Cu}$ occurs, forming an alloy, and/or that $\mathrm{Cu}$ is covering most of the noble metal, which may result in a strong limitation in the amount of $\mathrm{H}_{2}$ chemisorbed in the bimetallic catalyst. In addition, it has been reported [25] that the heat of adsorption during CO adsorption microcalorimetry experiments using a $1 \% \mathrm{Pd}-0.3 \% \mathrm{Cu}$ catalyst supported on an activated carbon (similar to that used in this work) decreases when compared to the Pd monometallic catalyst. This behavior was observed for catalysts heat treated at or above $200{ }^{\circ} \mathrm{C}$, which was explained by the formation of alloys. Such observations have also been confirmed by XRD [26]. Thus, since the catalysts used in this study were heat treated at $200{ }^{\circ} \mathrm{C}$, the different activities obtained in the experiments with the physical mixtures and bimetallic catalysts could be related with some alloy formation in the bimetallic catalyst leading to a decrease in the bromate reduction, which is

242 known to involve the dissociation of hydrogen on the surface of the noble metal [7, 17]. SEM/EDS data show that the particles on the surface of the activated carbon contain both metals. This was observed for the bimetallic catalysts and for the physical mixtures of monometallic catalysts after reaction. Similar results were reported for the same type of catalysts when physical mixtures where used in the nitrate reduction

247 [22], where the physical mixture of $\mathrm{Pd}$ and $\mathrm{Cu}$ catalysts performs equal or even better 248 than the corresponding bimetallic catalyst. Thus, it is possible to conclude that for the $\mathrm{Pd}-\mathrm{Cu}$ pair, while there is an improvement in the bromate reduction when compared with the $\mathrm{Pd}$ monometallic catalyst, the activity of the bimetallic catalyst could be partially hindered by the interaction between the $\mathrm{Cu}$ and $\mathrm{Pd}$ on the surface of the activated carbon support. An additional experiment was made using homogeneous $\mathrm{Cu}^{2+}$ as catalyst, where an amount equal to that present on the corresponding activated carbon supported catalysts was used. Only a residual improvement of the performance was achieved when compared with the experiment only with $\mathrm{H}_{2}$. Thus, 
the leaching of $\mathrm{Cu}$ into solution should not contribute significantly to the reduction of bromate in the case of the physical mixtures of monometallic $\mathrm{Pd}$ and $\mathrm{Cu}$ catalysts.

Different proportions of the pair $\mathrm{Pd}-\mathrm{Cu}$ as a bimetallic catalyst were tested in the catalytic reduction of bromate, and the removals obtained after 10 minutes of reaction are depicted in Figure 7 as a function of the atomic percentage of copper. Since the removal of bromate was complete after 30 minutes of reaction for all the proportions, an intermediate stage of reaction was selected to allow the comparison between the catalysts.

The performance of the bimetallic Pd-Cu catalysts with different loadings of both metals can be arranged in the following order: $1 \% \mathrm{Pd}-2 \% \mathrm{Cu}>1 \% \mathrm{Pd}-1 \% \mathrm{Cu} \approx 1 \% \mathrm{Pd}-$ $0.6 \% \mathrm{Cu}>1 \% \mathrm{Pd} \approx 2 \% \mathrm{Pd}-1 \% \mathrm{Cu}>1 \% \mathrm{Pd}-0.3 \% \mathrm{Cu}>1 \% \mathrm{Pd}-5 \% \mathrm{Cu} \approx 1 \% \mathrm{Pd}-0.1 \% \mathrm{Cu}$. When considering the atomic compositions presented, it is clear that a fraction of $\mathrm{Cu}$ at least equal to 0.5 is needed to improve the performance of the bimetallic catalyst relatively to the monometallic palladium catalyst. However, a large atomic fraction was shown to actually hinder the reduction rate of bromate (see $1 \% \mathrm{Pd}-5 \% \mathrm{Cu} / \mathrm{AC}$ ). It has been suggested for the $\mathrm{Pd}$-Cu bimetallic catalysts supported on activated carbon that the increase in the relative amount of the promoter metal decreases the availability of isolated noble metal particles [26]. Additionally, it has been observed than on a $\mathrm{Pd}-\mathrm{Cu}$ catalyst, applied to the catalytic hydrogenation of nitrite, the Pd promotes the dissociation of $\mathrm{H}_{2}$ to react with nitrite ions, while also reducing oxidized $\mathrm{Cu}$, which is then able to participate in the reaction, thus increasing the reaction rate by providing two active centers for reaction [13]. In regard of the textural characterization of the catalysts, particularly the information relative to metal particle size, significant changes have not been detected $[26,27]$. Therefore, the presence of the promoter metal increases the reactivity of the system on a certain range of atomic ratios; outside this interval the available noble metal surface necessary to interact with hydrogen and bromate ion decreases $[25,26]$. It has been observed that the addition of $\mathrm{Cu}$ to supported Pd catalysts reduces the availability of high coordination sites for reaction [28]. The low coordination sites, which become more predominant on the Pd surface with the addition of $\mathrm{Cu}$, are known to have higher activity in hydrogenation reactions $[29,30]$. This behavior has been observed in the reduction of nitrates over $\mathrm{Pd}-\mathrm{Cu}$ 
287 bimetallic catalysts, where the selectivity to the desired product (nitrogen) is hurt due

288 to over hydrogenation [31]. In the case of bromate reduction, the conversion into 289 bromide is always complete; so there is an improvement on the reaction rate when $\mathrm{Cu}$ 290 is coupled with Pd. However, when the ratio of $\mathrm{Cu}$ to $\mathrm{Pd}$ is too high, the performance 291 of the catalyst decreases, probably because the low coordination sites on the $\mathrm{Pd}$ 292 surface become blocked by the added $\mathrm{Cu}$.

293 The comparison of the performance of the bimetallic catalyst with different loadings 294 (Figure 7) with the performance of the physical mixtures of the same pair (Figure 6) is 295 useful to better understand the role of the bimetallic catalysts in the reduction of bromate in water using hydrogen. The performance of the physical mixture of the pair $\mathrm{Pd}-\mathrm{Cu}$ is noticeably better than that of the corresponding bimetallic catalyst, regardless of the $\mathrm{Pd} / \mathrm{Cu}$ ratio chosen (results not shown). It has been shown that for the remaining pairs tested, the addition of other metal did not improve the removal of bromate obtained with the noble metal monometallic catalyst. Thus, it seems that the utilization of a bimetallic catalyst is only beneficial for this reaction in specific cases. Accordingly, for the $\mathrm{Pd}$-Cu pair, the addition of $\mathrm{Cu}$ as promoter metal to the Pd catalyst improves the reaction rate due to interaction between the metals, when they are found in a specific range of atomic ratios; this was not observed for the remaining metal pairs studied. The observed increase in performance of the physical mixture of $\mathrm{Pd}$ and $\mathrm{Cu}$ monometallic catalysts supported on $\mathrm{AC}$ when compared with the corresponding bimetallic catalyst might then also be attributed to the close interaction of $\mathrm{Pd}$ and $\mathrm{Cu}$ coming from solution (leached from the $\mathrm{Cu}$ monometallic catalyst) in an atomic ratio that is highly favorable for the studied reaction. On the other hand, in the mild experimental conditions used (room P and T), alloy formation on the surface of

$311 A C$ is not to be expected. It is possible that the higher performance of the physical mixture is related to the close interaction between $\mathrm{Pd}$ and $\mathrm{Cu}$ (leached from $1 \% \mathrm{Cu} / \mathrm{AC}$ ) without the formation of alloys that might hinder the hydrogen chemisorption capability of Pd, as likely occurs when the bimetallic catalysts are heat treated and reduced at $200{ }^{\circ} \mathrm{C}$. 
317 Several bimetallic pairs supported on activated carbon were studied as catalysts for 318 the hydrogen reduction of bromate in water. All the tested catalysts showed 319 remarkable activity on the reduction of bromate under hydrogen. Furthermore, the 320 conversion of bromate into bromide was observed to be complete for all the cases, without formation or accumulation of by-products in solution.

322 The $\mathrm{Pd}-\mathrm{Cu}$ pair was shown to be the most promising catalyst, completely converting 323 bromate in less than 10 minutes of reaction. Most of the other pairs resulted in reduced activity when compared to the corresponding monometallic noble metal catalysts.

326 Experiments using physical mixtures were carried out, and it was observed that the

327 presence of a second metal, in most cases, can decrease the available surface of the noble metal for reaction, or can decrease the capacity of the most active metal to adsorb hydrogen. However, for the Pd-Cu pair, the experiment carried out using the corresponding physical mixture outperformed the bimetallic catalyst; nevertheless, during the physical mixtures experiments, in-situ formation of bimetallic catalyst was observed. This suggests that the interaction between the two metals improved the removal of bromate.

The influence of the composition in Pd-Cu catalysts was investigated, and it was shown that some improvement can be obtained regarding the reduction of bromate ion in water, when this pair was compared with the Pd monometallic catalyst. The improved performance of the $\mathrm{Pd}-\mathrm{Cu}$ catalyst was observed to only occur in a specific range of atomic ratios.

\section{Acknowledgments}

340 Support for this work was provided by LSRE/LCM LA financing from Programa

341 Operacional Factores de Competitividade (COMPETE), project FCOMP-01-0124-FEDER342022706 (Ref. FCT Pest-C/EQB/LA0020/2011), by Fundação para a Ciência e a 343 Tecnologia (FCT) and Fundo Europeu de Desenvolvimento Regional (FEDER). J. Restivo 344 and O.S.G.P. Soares thank FCT for their research grants (SFRH/BD/95751/2012 and SFRH/BPD/80435/2011, respectively). 
347 [1] W.J. Huang, Y.L. Cheng, Effect of characteristics of activated carbon on removal of 348 bromate, Sep. Purif. Technol., 59 (2008) 101-107.

349 [2] M.J. Kirisits, V.L. Snoeyink, J.C. Kruithof, The reduction of bromate by granular 350 activated carbon, Water Res., 34 (2000) 4250-4260.

351 [3] D.B. Thakur, R.M. Tiggelaar, Y. Weber, J.G.E. Gardeniers, L. Lefferts, K. Seshan, 352 Ruthenium catalyst on carbon nanofiber support layers for use in silicon-based structured microreactors. Part II: Catalytic reduction of bromate contaminants in aqueous phase, Appl. Catal., B, 102 (2011) 243-250.

355 [4] World Health Organization, Bromate in drinking-water;Background document for 356 preparation of WHO guidelines for drinking-water quality., Geneva, 2003.

357 [5] United States Environmental Protection Agency, Public health goals for chemicals in 358 drinking water - Bromate, California, 2009.

359 [6] International Agency for Cancer Research, Agents Classified by the IARC 360 Monographs, Volumes 1-106, Lyon, 2012.

361 [7] H. Chen, Z. Xu, H. Wan, J. Zheng, D. Yin, S. Zheng, Aqueous bromate reduction by 362 catalytic hydrogenation over Pd/Al2O3 catalysts, Appl. Catal., B, 96 (2010) 307-313.

363 [8] D. Duonghong, W. Erbs, L. Shuben, M. Grätzel, Efficient redox catalysis by RuO2 in 364 the generation of oxygen and bromine from aqueous bromate solutions, Chem. Phys. 365 Lett., 95 (1983) 266-268.

366 [9] Y. Marco, E. García-Bordejé, C. Franch, A.E. Palomares, T. Yuranova, L. Kiwi367 Minsker, Bromate catalytic reduction in continuous mode using metal catalysts supported on monoliths coated with carbon nanofibers, Chem. Eng. J., 230 (2013) 605611.

370 [10] A. Mills, G. Meadows, Heterogeneous redox catalysis: A novel route for removing 371 bromate ions from water, Water Res., 29 (1995) 2181-2185. 
372 [11] A.E. Palomares, C. Franch, T. Yuranova, L. Kiwi-Minsker, E. García-Bordeje, S. 373 Derrouiche, The use of $\mathrm{Pd}$ catalysts on carbon-based structured materials for the 374 catalytic hydrogenation of bromates in different types of water, Appl. Catal., B, 146 375 (2014) 186-191.

376 [12] P. Zhang, F. Jiang, H. Chen, Enhanced catalytic hydrogenation of aqueous bromate 377 over Pd/mesoporous carbon nitride, Chem. Eng. J., 234 (2013) 195-202.

378 [13] W. Gao, J. Chen, X. Guan, R. Jin, F. Zhang, N. Guan, Catalytic reduction of nitrite 379 ions in drinking water over Pd-Cu/TiO2 bimetallic catalyst, Catal. Today, 93-95 (2004) 380 333-339.

381

[14] A. Pintar, J. Batista, J. Levec, Potential of mono- and bimetallic catalysts for liquid382 phase hydrogenation of aqueous nitrite solutions, Water Sci. Technol., 37 (1998) 177383 185.

384

[15] O.S.G.P. Soares, J.J.M. Órfão, M.F.R. Pereira, Activated carbon supported metal 385 catalysts for nitrate and nitrite reduction in water, Catal. Lett., 126 (2008) 253-260.

[16] K. Wada, T. Hirata, S. Hosokawa, S. Iwamoto, M. Inoue, Effect of supports on Pd387 $\mathrm{Cu}$ bimetallic catalysts for nitrate and nitrite reduction in water, Catal. Today, 185 388 (2012) 81-87.

[17] J. Restivo, O.S.G.P. Soares, J.J.M. Órfão, M.F.R. Pereira, Metal assessment for the catalytic reduction of bromate in water under hydrogen, (2014) submitted.

[18] M. Cerro-Alarcón, A. Maroto-Valiente, I. Rodríguez-Ramos, A. Guerrero-Ruiz, 392 Surface study of graphite-supported Ru-Co and Ru-Ni bimetallic catalysts, Appl. Catal., A, 275 (2004) 257-269.

[19] W. Yi, T. Kasuga, I. Mikami, Y. Kamiya, T. Okuhara, Palladium-copper/hydrophobic 395 active carbon as a highly active and selective catalyst for hydrogenation of nitrate in water, Chem. Lett., 36 (2007) 994-995.

397 [20] J.C. Serrano-Ruiz, G.W. Huber, M.A. Sánchez-Castillo, J.A. Dumesic, F. RodríguezReinoso, A. Sepúlveda-Escribano, Effect of Sn addition to Pt/CeO2-Al2O3 and Pt/Al2O3 
399

400

401

402

403

404

405

406

407

408

409

410

411

412

413

414

415

416

417

418

419

420

421

422

423

424

425

catalysts: An XPS, 119Sn Mössbauer and microcalorimetry study, J. Catal., 241 (2006) 378-388.

[21] J.C. Serrano-Ruiz, A. Sepúlveda-Escribano, F. Rodríguez-Reinoso, Bimetallic PtSn/C catalysts promoted by ceria: Application in the nonoxidative dehydrogenation of isobutane, J. Catal., 246 (2007) 158-165.

[22] O.S.G.P. Soares, J.J.M. Órfão, M.F.R. Pereira, Nitrate reduction with hydrogen in the presence of physical mixtures with mono and bimetallic catalysts and ions in solution, Appl. Catal., B, 102 (2011) 424-432.

[23] L. Calvo, M.A. Gilarranz, J.A. Casas, A.F. Mohedano, J.J. Rodriguez, Denitrification of Water with Activated Carbon-Supported Metallic Catalysts, Ind. Eng. Chem. Res., 49 (2010) 5603-5609.

[24] C. Crisafulli, S. Galvagno, R. Maggiore, S. Scirè, A. Saeli, Performance of supported Ru-Cu bimetallic catalysts prepared from nitrate precursors, Catal. Lett., 6 (1990) 7783.

[25] O.S.G.P. Soares, J.J.M. Órfão, J. Ruiz-Martínez, J. Silvestre-Albero, A. SepúlvedaEscribano, M.F.R. Pereira, Pd-Cu/AC and Pt-Cu/AC catalysts for nitrate reduction with hydrogen: Influence of calcination and reduction temperatures, Chem. Eng. J., 165 (2010) 78-88.

[26] O.S.G.P. Soares, J.J.M. Órfão, M.F.R. Pereira, Bimetallic catalysts supported on activated carbon for the nitrate reduction in water: Optimization of catalysts composition, Appl. Catal., B, 91 (2009) 441-448.

[27] N. Barrabes, J. Just, A. Dafinov, F. Medina, J.L.G. Fierro, J.E. Sueiras, P. Salagre, Y. Cesteros, Catalytic reduction of nitrate on $\mathrm{Pt}-\mathrm{Cu}$ and $\mathrm{Pd}-\mathrm{Cu}$ on active carbon using continuous reactor The effect of copper nanoparticles, Appl. Catal., B, 62 (2006) 77-85.

[28] F. Gauthard, F. Epron, J. Barbier, Palladium and platinum-based catalysts in the catalytic reduction of nitrate in water: effect of copper, silver, or gold addition, J. Catal., 220 (2003) 182-191. 
426 [29] J.K. Chinthaginjala, A. Villa, D.S. Su, B.L. Mojet, L. Lefferts, Nitrite reduction over

427 Pd supported CNFs: Metal particle size effect on selectivity, Catal. Today, 183 (2012) $428 \quad 119-123$.

429 [30] Y. Yoshinaga, T. Akita, M. Ikko, O. Toshio, Hydrogenation of Nitrate in Water to 430 Nitrogen over Pd-Cu Supported on Active Carbon, J. Catal., 207 (2002) 37-45.

431 [31] F. Epron, F. Gauthard, C. Pinéda, J. Barbier, Catalytic Reduction of Nitrate and 432 Nitrite on Pt-Cu/Al2O3 Catalysts in Aqueous Solution: Role of the Interaction between 433 Copper and Platinum in the Reaction, J. Catal., 198 (2001) 309-318.

434 


\section{LIST OF TABLES}

436 Table 1. Bimetallic catalysts supported on AC.

437 Table 2. Textural characterization of the activated carbon (AC) and some of the 438 catalysts.

439 
Table 1

\begin{tabular}{|c|c|}
\hline \multicolumn{2}{|c|}{$1 \%$ noble metal $-1 \%$ second metal } \\
\hline Pd & $\mathrm{Cu} ; \mathrm{Fe} ; \mathrm{Sn} ; \mathrm{Zn}$ \\
\hline $\mathrm{Pt}$ & $\mathrm{Cu} ; \mathrm{Sn}$ \\
\hline $\mathrm{Ru}$ & $\mathrm{Cu} ; \mathrm{Ni}$ \\
\hline $\mathrm{Rh}$ & Sn \\
\hline Ir & $\mathrm{Cu}$ \\
\hline $\mathrm{x} \% \mathrm{Pd}$ & $\mathrm{x} \% \mathrm{Cu}$ \\
\hline 1 & $0.1 ; 0.3 ; 0.6 ; 1 ; 2 ; 5$ \\
\hline 2 & 1 \\
\hline
\end{tabular}

441

442

443

444 
Table 2

\begin{tabular}{cccc}
\hline \multirow{2}{*}{ Sample } & $\mathrm{S}_{\mathrm{BET}}$ & $\mathrm{S}_{\text {meso }}{ }^{\mathrm{a}}$ & $\mathrm{V}_{\text {micro }}{ }^{\mathrm{a}}$ \\
& & & \\
& $\left(\mathrm{m}^{2} / \mathrm{g}\right)$ & $\left(\mathrm{m}^{2} / \mathrm{g}\right)$ & $\left(\mathrm{cm}^{3} / \mathrm{g}\right)$ \\
\hline AC & 869 & 97 & 0.318 \\
& & & \\
2\%Pd-1\%Cu/AC & 870 & 90 & 0.330 \\
& & & \\
1\%Pt-1\%Cu/AC & 876 & 168 & 0.275 \\
& & & \\
1\%Rh-1\%Cu/AC & 862 & 104 & 0.280 \\
\hline
\end{tabular}

$446{ }^{a}$ Micropore volume $\left(\mathrm{V}_{\text {micro }}\right)$ and mesopore surface area $\left(\mathrm{S}_{\text {meso }}\right)$ calculated by the $\mathrm{t}$ 447 method.

448 


\section{LIST OF FIGURES}

450 Figure 1. TEM micrograph of $1 \% \mathrm{Pd}-1 \% \mathrm{Cu} / \mathrm{AC}$ bimetallic catalyst.

451 Figure 2 - Evolution of the dimensionless concentration of bromate for reduction 452 experiments using $\mathrm{H}_{2}$ and bimetallic palladium catalysts supported on activated 453 carbon.

454 Figure 3 - Evolution of the dimensionless concentration of bromate for reduction 455 experiments using $\mathrm{H}_{2}$ and bimetallic catalysts containing $\mathrm{Cu}$, supported on activated 456 carbon.

457 Figure 4 - Evolution of the dimensionless concentration of bromate for reduction 458 experiments using $\mathrm{H}_{2}$ over $\mathrm{Pd}$ and $\mathrm{Pt}(\mathrm{a})$, and $\mathrm{Ru}$ and $\mathrm{Rh}(\mathrm{b})$, bimetallic catalysts 459 containing $\mathrm{Sn}$ or $\mathrm{Ni}$, supported on activated carbon.

460 Figure 5 - EDS spectra of metallic particles found in the surface of the catalysts after 461 reaction: a) $1 \% \mathrm{Pd}-1 \% \mathrm{Cu} / \mathrm{AC}$; b) $1 \% \mathrm{Pd} / \mathrm{AC}+1 \% \mathrm{Cu} / \mathrm{AC}$; c) $1 \% \mathrm{Pd} / \mathrm{AC}+1 \% \mathrm{Cu} / \mathrm{AC}$ 462 (copper particle).

463 Figure 6 - Evolution of the dimensionless concentration of bromate for reduction 464 experiments using $\mathrm{H}_{2}$ over the bimetallic $\mathrm{Pd}-\mathrm{Cu}$ catalyst and physical mixture of the 465 corresponding monometallic catalysts.

466 Figure 7 - Removal of bromate after 10 min during reduction experiments using $\mathrm{H}_{2}$ 467 over different bimetallic Pd-Cu catalysts vs. atomic copper content. 
$469 \quad$ Figure 1

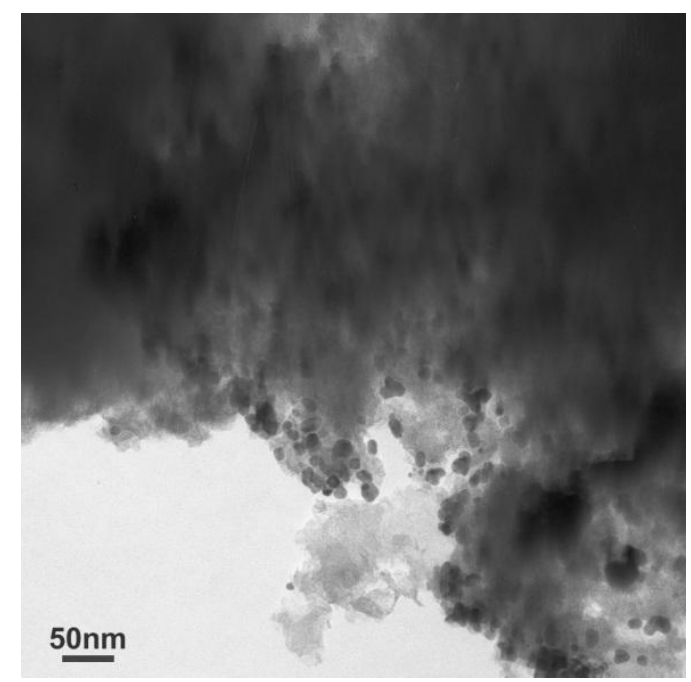

471 
$472 \quad$ Figure 2

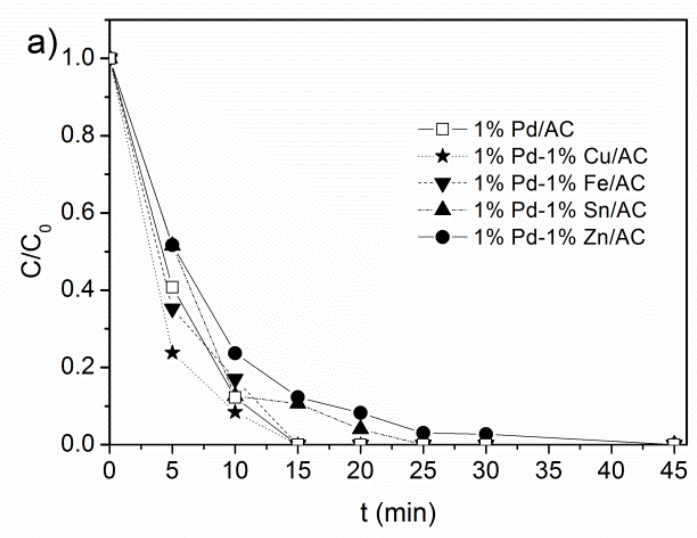

473

474 
$475 \quad$ Figure 3

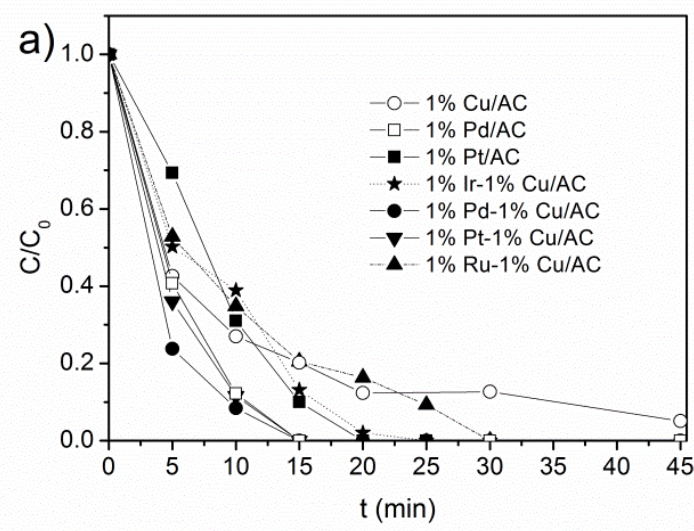

476 
Figure 4

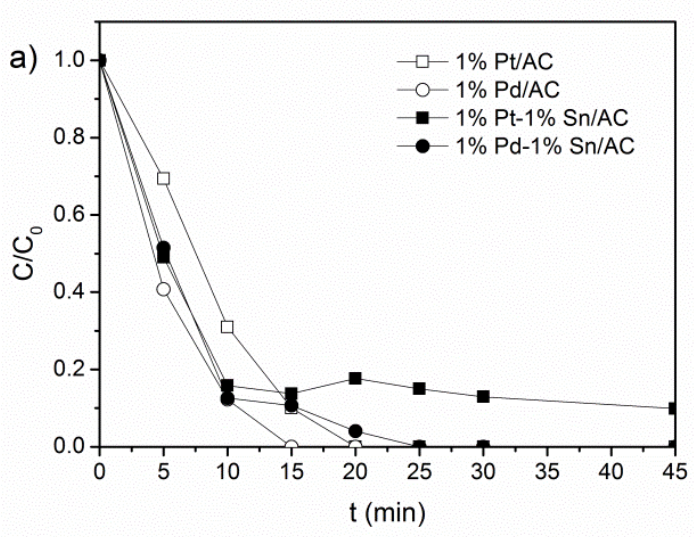

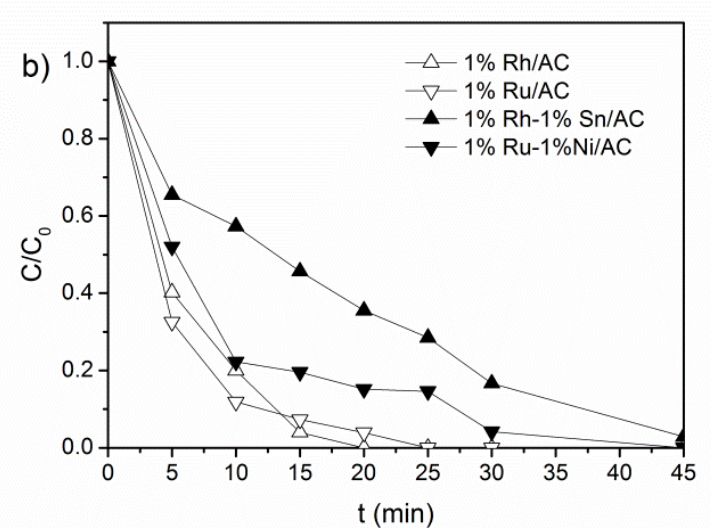

479 
Figure 5
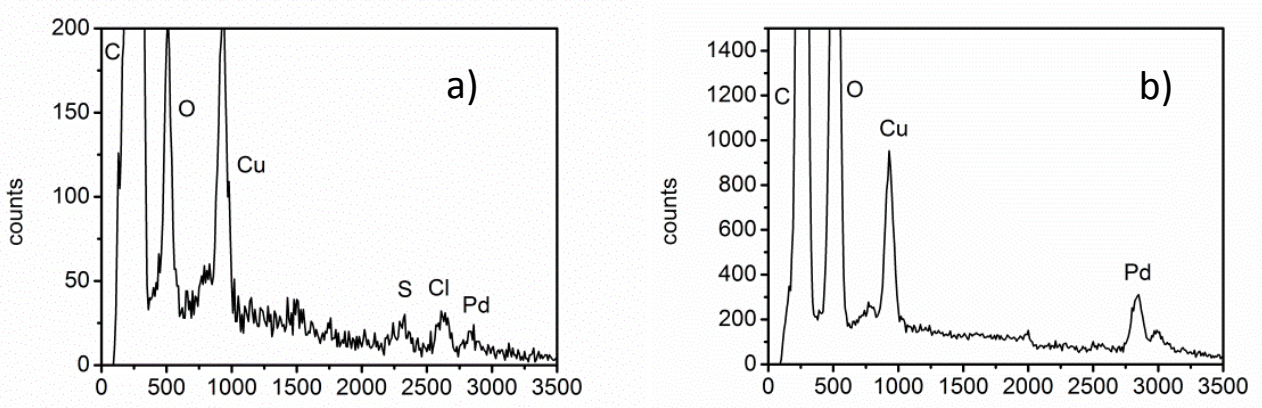

482

enerav (eV)

enerav $(\mathrm{eV})$

483

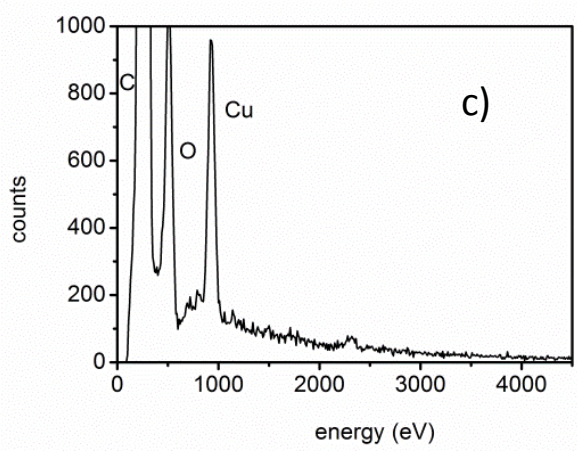

484

485 
Figure 6

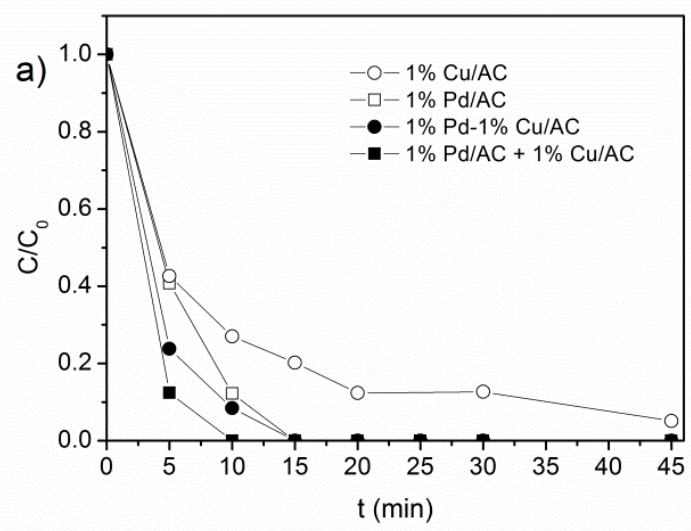

487

488 


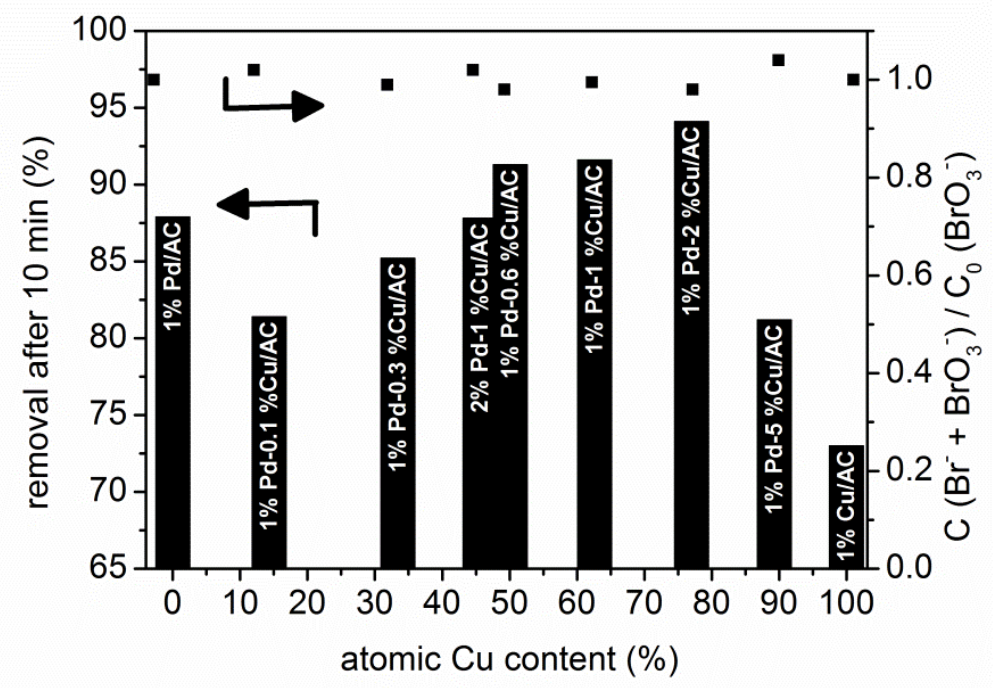

490 